\title{
О СОСТОЯНИИ МЕТРОЛОГИЧЕСКОГО ОБЕСПЕЧЕНИЯ ОЦЕНКИ СООТВЕТСТВИЯ И КАЧЕСТВА ПРОДУКЦИИ В ПРОЦЕССЕ ПРОИЗВОДСТВА
}

\author{
Владимир ПРОНЯкИН, Александр КомШИН
}

Ключевые слова: конкурентоспособность, соответствие продукции, метрологическое обеспечение
Важнейшей задачей промышленности является создание и выпуск конкурентоспособной продукции мирового уровня. Инструментом подтверждения качества продукции установленным требованиям в процессе производства является оценка соответствия продукции. Соответствие продукции установленным требованиям подтверждается метрологическим обеспечением (измерения, контроль и испытания) и реализуется комплексом мероприятий, частью которых является обеспечение единства измерений (поверка и калибровка СИ, аттестация оборудования).

Наличие поверенных и калиброванных средств измерений в процессе оценки соответствия является необходимым, но недостаточным условием. Метрологическое обеспечение - это комплекс мероприятий для обеспечения получения и подтверждения достоверных результатов измерений, например:

$\rightarrow$ разработка норм точности для экономически оптимальной минимизации риска потребителя получить браковочное изделие как годное изготовителю для оптимизации затрат;

$\rightarrow$ завоевание доверия заказчика и рынка тем, что качество продукции соответствует заявленным требованиям, а изделие конкурентоспособно, что подтверждается высокопрофессиональным метрологическим обеспечением.

В настоящее время в промышленности в подавляющем большинстве господствуют технические измерения. Метрологическое обеспечение как комплекс мероприятий, обе- спечивающий оценку соответствия продукции, отсутствует. Основным является выбор средства измерения, которое, как правило, определяет технолог, что непрофессионально. Наряду с этим, для реализации метрологического обеспечения и подготовки метролога преподается по направлению «Метрология и метрологическое обеспечение» более 20 профессиональных дисциплин.

Причиной сложившейся ситуации является техническая некомпетентность многих представителей промышленности, предпринимателей, работодателей и чиновников разных уровней. В настоящее время у руководителей господствует устойчивое представление о том, что метрология в промышленности - это только обеспечение единства измерений, и главное, чтобы средства измерений были поверены и калиброваны. Но в производстве применяются поверенные и калиброванные средства измерений. Тогда должен возникнуть вопрос: какие задачи решает метрологическое обеспечение и специалист-метролог в процессе производства?

Метрологическое обеспечение является инструментом оценки соответствия продукции (измерения, контроль и испытания), а как единая система она структурно разорвана и, как правило:

$\rightarrow$ отделы технического контроля подчиняются заместителю директора по качеству, службе качества;

$\rightarrow$ службы испытаний подчиняются главному инженеру;

$\rightarrow$ отделы главного метролога занимаются поверкой, калибровкой и метрологической экспертизой. 
При этом отделы главного метролога, как правило, не отвечают за оценку соответствия продукции, конечное качество изделий и метрологическое обеспечение производства. Отвечает за это ОТК, у которого нет задач метрологического обеспечения, а реализуются технические измерения. Профессионально для решения задач метрологического обеспечения готовят специалистов-метрологов. В связи с этим заявление о высоком качестве продукции несостоятельны. Это подтверждается всей практикой отечественной промышленности.

Основой принятия всех решений о качестве выпускаемой продукции является измерительная информация и контроль (в том числе, испытания), и их организация должна осуществляться высокопрофессиональными специалистами-метрологами. Отсутствие понимания этого приводит к тому, что метрология в промышленности понимается только как часть обеспечения единства измерений (поверка и калибровка), где не требуется много метрологов. Следствием таких представлений у руководителей является то, что:

1. Существует серьезная проблема достижения высокого уровня, качества и конкурентоспособности отечественной продукции на мировом рынке, которое недостижимо без квалифицированного метрологического обеспечения оценки соответствия продукции в процессе производства.

2. В промышленности отсутствует необходимое количество кадров (специалистов-метрологов) для реализации метрологического обеспечения оценки соответствия продукции в процессе производства.

3. На запросы Минпромторга России к промышленности о потребности в кадрах (специалистахметрологах) руководители предприятий и организаций отвечают, что метрологи не нужны, и при этом говорят о качестве продукции.

4. В настоящее время по выборке 95 ведущих университетов (2019 год) по контрольным цифрам приема (бюджетные места) по направлениям подготовки 27.03.01 «Стандартизация и метрология», 27.04 .01 «Стандартизация и метрология» (система бакалавр-магистр), куда входит направленность «Метрология и метрологическое обеспечение», анализ показал следующие результаты:

$\rightarrow$ в настоящее время только $34 \%$ вузов выпускают бакалавров,

$\rightarrow$ только $13 \%$ вузов готовят магистров и, в целом, в два раза меньше, чем бакалавров, что резко снижает уровень подготовки специалистов и имеется острейший дефицит в промышленности высокопрофессиональных специалистов-метрологов.

5. Министерство науки и высшего образования в связи с изложенными проблемами поступательно уменьшает количество бюджетных мест и, соответственно, количество выпускников специа- листов-метрологов в образовательной группе 27. XX.XX «Управление в технических системах», где среди 10 направлений находится 27.03.01 и 27.04.01 «Стандартизация и метрология», и только часть имеет направленность «Метрология и метрологическое обеспечение». Бюджетные места при этом делятся на всю группу. Платное обучение дорогое и недоступно многим.

В связи с условиями рынка в высшем техническом образовании и уменьшением количества бюджетных мест, когда существование метрологических кафедр зависит от интереса выпускников школ, а не интересов государства, начинается процесс исчезновения метрологических специальностей и далее метрологических кафедр.

Для реализации профессионального метрологического обеспечения оценки соответствия продукции высокопрофессиональными кадрами (специалистами-метрологами) необходимо специальность «Метрология и метрологическое обеспечение» выделить и вернуть в специалитет или иметь бюджетные места в системе бакалавр-магистр (27.03.01 и 27.04.01) в соотношении 1:1 и выделять бюджетные места отдельной строкой.

Без комплексного решения изложенных проблем и применения мировых практик невозможно достигнуть отечественной промышленностью результативности развитых стран в обеспечении высокого качества продукции и ее конкурентоспособности.

Наилучшая мировая практика формирования продукции основывается на метрологическом сопровождении процесса создания конечного продукта и получения достоверных метрологических данных о нем. Персонал, обеспечивающий процессы изготовления продукта, имеет там достаточную и необходимую метрологическую компетентность, которая верифицируется, тестируется и поддерживается высококвалифицированными, компетентными специалистами, подготовленными специализированными высшими учебными заведениями, формирующими метрологические службы. Они во многом определяют конкурентоспособность продукции и ее превосходство на рынке.

Таким, образом, проблема обеспечения высокого качества отечественной продукции и его профессионального метрологического обеспечения выросла в проблему национальной безопасности.

\section{ПРонякин Владимир Ильич -}

доктор технических наук, профессор, заведующий кафедрой «Метрология и взаимозаменяемость» мГтУ им. Н.Э. Баумана

\section{комшин Александр Сергеевич -}

доктор технических наук, профессор кафедры «Метрология и взаимозаменяемость» МГТУ им. Н. Э. Баумана 